\title{
So You Need To Choose a TeXtbook: An Investigation INTO FIRST-YEAR ENGINEERING CALCULUS TEXTBOOKS IN CANADA
}

\author{
Sasha Gollish, Anne Mather, and Bryan Karney \\ University of Toronto \\ s.gollish@mail.utronto.ca
}

\begin{abstract}
-
The motivation for this paper was two-fold; first to examine the types of textbooks that are being used to teach calculus to undergraduate engineering students in the Canadian Universities; and, second, to assess whether these textbooks do a 'good job' at teaching calculus to undergraduate engineering students.

The calculus textbooks used by engineering faculties across Canada were found through an online search, either by downloading a course syllabus or through a course website. Research into these various textbooks was done through the various textbook company websites and other articles. A review of the various textbooks was provided. In addition, select calculus textbooks were selected for a more thorough review of teaching 'differentiation.'

More often universities are choosing calculus textbooks that are rooted in engineering.

"The art of teaching is the art of assisting discovery." Mark Van Doren
\end{abstract}

Keywords: Calculus, Mathematics, Engineering Education, Curriculum, Textbook.

\section{INTRODUCTION}

Imagine that you have been assigned a course to teach: introductory calculus for engineering students, for example. You imagine that you can teach it well, in a way that will help struggling students and motivate keen ones. One of the tasks you must undertake is to choose a textbook for the course. This textbook will help you and the students brush up on the material, give you a scope and structure for the classes, and provide students with additional material. Which is the best one? How do you choose the right textbook?

Calculus, and all other mathematics, is a requirement for graduation from an accredited undergraduate engineering program, not only in Canada, but in all accredited undergraduate engineering programs across the globe; mathematics is foundational to most, if not all, engineering courses. As part of the Washington Accord of the International Engineering Alliance (IEA), Engineers Canada holds accredited Canadian undergraduate engineering programs to a standard of learning; as members of this accord Canadian engineering programs are recognized as comparable with all other member countries [1].

The IEA, "is an umbrella organisation for six multilateral agreements which establish and enforce amongst their members internationally-benchmarked standards for engineering education and what is termed "entry level" competence to practise engineering" [2]. The Washington Accord "is a self-governing, autonomous agreement between national organizations that provide external accreditation to tertiary educational programmes that qualify their graduates for entry into professional engineering practice" [2]. Atop the list is "Engineering Knowledge: [an ability to] apply knowledge of mathematics, natural science, engineering fundamentals"[2]; mathematics is the foundation of engineering.

Therefore, the authors believe that it is no mistake that mathematics falls under the first accreditation criteria in Canada, 'A knowledge base for engineering: demonstrated competence in university level mathematics, natural sciences, engineering fundamentals, and specialized engineering knowledge appropriate to the program'[1]. Even in the natural sciences one needs mathematics for problem solving. Moving forward, mathematics courses in engineering will be referred to as engineering mathematics (EM).

Every undergraduate engineering program in Canada has foundational EM courses, calculus and linear algebra; for the purposes of this paper the authors have chosen to focus on first-year calculus. For simplicity, we will describe the breakdown of a typical course, one which the authors believes accurately represents a typical undergraduate EM course (i.e. calculus or linear algebra). 
As shown in the figure below, each course can be thought to have in-classroom and out-of-classroom components. In-classroom would include any lectures, tutorials, laboratory work, workshops, etc. Out-of-classroom is anything the student does outside of these; i.e., homework, textbook reading(s), research, on-line learning, or extra tutoring. The artifacts include textbooks, course notes, course websites, course outlines, etc (i.e., anything supplemental that supports learning). Textbooks, can and should be used, to tie the in-classroom and out-ofclassroom; but is that always the case?

\section{BACKGROUND}

\subsection{Some Reflections on Teaching Mathematics}

We have all, at some point, taken courses that we have found extremely engaging, that have drawn us into a particular topic and pushed us to explore further; we have undoubtedly taken others that have bored us or, worse, driven us away from some area of study. This interest - or lack thereof - is often, though not always, attributed to the teacher: good teachers can motivate and inspire students, whereas poor ones turn students away. Another common conception of motivation is that students come to courses either interested in the material or not; one student may find a class extremely engaging, whereas the student next to them finds it dull. These two positions have been referred to in motivational research as extrinsic and intrinsic motivation, though it has been argued [3] that they are not mutually exclusive, that the factors behind academic motivation can exist between these two extremes. Indeed, we take that view here, that while students can and do enter courses with greater and lesser degrees of interest in the material, educators play an important role in presenting the material in an engaging way. More specifically, we suggest that the way in which course content is framed - the context in which it is presented - is fundamentally important. Whatever textbook you choose will have to present that material in a way that makes connections both within the course and with students' prior knowledge and other learning.

Mathematics classes, in particular, elucidate this point. It is easy to contrast math students who are intrinsically motivated with those who are not; the former love the class and breeze through the homework, whereas the latter claims to be "not a math person" and gives up even before the work has been assigned. You imagine that both of these students will likely be present in your upcoming course, and that whatever textbook you choose will have to appeal to both. On the other hand, Boaler's [4] recent book offers numerous suggestions for teachers about how to make math inspiring to students, affirming that everyone can learn math and that teachers have the power to make it accessible. Thus, whatever textbook you choose will have to help you do just this.
EM is a unique course in undergraduate engineering education. It can at times feel disconnected from the curriculum, with teaching examples and homework rooted in abstract engineering, whereas students could and would learn better if these examples were applied and rooted in engineering. Students in engineering are often 'math people,' but their experience in undergraduate EM leaves them feeling unmotivated to study mathematics; students merely want to 'get through the class' and move on.

We suggest that one way to make EM accessible, engaging, and motivating is to present it in a way that helps students connect to it, regardless of whether or not students come into the class with any inherent interest. Thus, your task in choosing a mathematics textbook for engineering students must help you frame mathematics in a way that engineers connect to it. We argue that the primary motivation for future engineers to learn mathematics is to make defensible, reasoned, responsible, ethical decisions. Whatever textbook you select should help students learn how to make defensible decisions based on their mathematical intuitions and calculation

\subsection{A Decision-Making Framework for Engineering Mathematics}

The reason that engineering students take mathematics courses is not that they are "weeder" courses, though they, unfortunately, have been perceived - if not explicitly and intentionally used - in this way. Instead, engineering students must learn that mathematical models are the best way to predict and compare the potential outcomes of various options without having to experiment directly on the world. As Karney and Mather describe it, "models act as stand-ins or substitutes for the reality of direct action and, in the 21 st century, such models are almost invariably hybrid mathematical and conceptual constructs showing through symbols an association between actions [...] and consequences" [5].

Students should not become rote mathematics masterminds; they must apply their mathematical skills in thoughtful and responsible ways. In this vein, Olin College has developed an engineering program that is extremely project-based, right from the first year. During the design of this program in the early 2000s, the study group stated that "if an engineer does not go out and actively use the tools he has been given to innovate or to solve problems, he will only be used as a resource for engineering skills and left out of the larger decision making processes" [6].

The motivation for teaching and learning mathematics within engineering programs is the presence of collective consequences of engineering decisions. If there were only individual consequences, we could skip the math. We could allow students to focus on design activities without emphasizing mathematical modelling. We could let them make decisions based on guesses about what could result from them. However, engineering decisions affect society as a whole, and mathematical modelling is the tool that 
allows engineers to make informed, thoughtful predictions and make ethical decisions based on these.

\subsection{Reflections on Textbooks}

What makes a good textbook? A good textbook is not merely a repository of knowledge or techniques; it is way to help a student think 'deeper' [7]. It is a link between what is discussed in the classroom to what the student does outside of the classroom (i.e., homework, assignments, tutorials, etc.). Before moving forward, it is useful to discuss, and distinguish, what we mean by a textbook. Textbooks are not well defined in the literature. If one thinks back to their education career there were lots of different textbooks in their lives; for example, from novels in English and Classics classes, readings (and backgrounds) for history or geography, to language textbooks just to name a few options [8].

What about mathematics and sciences textbooks? For this paper, we have defined a mathematics (or sciences) textbook, that has specific, albeit traditional, structure - with introductions explanations of a specific topic, supported with examples, problem sets, and answers in the appendix [8]. In the context of mathematics instruction, a good mathematics textbook not only builds on student's concepts of mathematics in an engaging way, but it also develops mathematical ideas by promoting deeper thinking [9]. Good EM textbooks need to go one further step, it's not just about deeper thinking but having examples from the textbook rooted in the various domains of engineering.

On the contrary, sometimes textbooks can be a disservice in teaching. "The danger with ready-made textbooks is that they can seem to absolve teachers of responsibility" [10]. And while a teacher may find that the textbook is excellent and helpful, that same textbook may not be a resource for some students [11]. In addition, "some students struggle with textbook reading, due to the difficult readability, challenging vocabulary, and concept overload of many textbooks [12], concept not foreign in EM textbooks.

Further, the trend in choosing textbooks is to default to whatever has been used before. Keenan [11] asserts that educators "are risk-averse [and] favour proven formulas"[11]. Along the same lines, even textbook authors and publishers are deeply influenced by previous textbooks; Herbel-Eisenmann [13] tells a story of a middle-school textbook that was intentionally meant to meet new national standards and thus differs from the conventions of previous texts; instead, the author found that the textbook was much the same and that it illustrated "how powerful the hegemony of traditional forms of discourse in mathematics curriculum materials can be" [13].

Even more cynically, it seems that professors can receive royalties for choosing particular textbooks. Bartlett [14] chronicles the story of a history professor who was offered $\$ 4,000$ by a publisher for reviewing a textbook in his course, provided the students each bought a copy. This is just one example of "a pattern of ethically questionable financial arrangements" [14] found in the competitive and lucrative textbook industry.

The authors would be remiss if we did not address the literature that duly points out how poorly students use textbooks: they read them both seldom and poorly. In a review of tertiary textbook usage and habits, Berry et al. [15] point out that college-level students do not spend a lot of time reading their textbooks, despite being aware of the importance of doing so [15]. More specifically, mathematics professors find much more meaning in textbooks than students [16], and undergraduate students have particular troubles reading academic mathematics texts for meaning and understanding [17]. Although we could not find any literature, anecdotally the authors note that textbooks are often used by the students solely for their problem sets. One should be aware that the textbook is as much (or more) for an instructor as than it is for the students.

So, choosing a textbook thoughtfully and meaningfully may be an uphill battle! Nevertheless, we offer some thoughts and counsel to you in your endeavour.

\section{METHODOLOGY}

This project is part of a bigger study regarding strengthening the relationship of mathematics and engineering in the undergraduate engineering curriculum. In the summer of 2016 the authors researched the first-year calculus textbooks used at the Canadian accredited universities; "there are 281 accredited engineering programs at 43 higher education institutions across Canada" [1]. First-year undergraduate engineering mathematics calculus course was chosen for investigation because it is large, general first-year course often taught by several instructors, some from an engineering background, others from mathematics [18].

Using the list of accredited universities across Canada, the information about the first-year engineering mathematics course textbooks was found on the course outline or website through a simple internet search (i.e. Google). Where it was not possible to find either a course outline or website, an email was sent to an institution. Not all institutions responded to the author's request for the textbook used to teach first-year calculus at the undergraduate level.

Specific 'demographic' data regarding a textbook was investigated, for instance, current edition, number of pages, authors, and publisher. The authors also applied a 'category' to each textbook, 'abstract' or 'applied' to delineate which textbooks were thought to teach toward the abstract (labelled 'abstract') or toward the applied and/or applied rooted in engineering examples (labelled 'applied). 
A more detailed comparison was made using four textbooks from the three types of 'category' as mentioned just above. Four textbooks in total were chosen: An 'abstract,' an 'applied,' and an 'applied rooted in engineering examples' and a fourth was chosen to compare the same textbook that addressed Early Transcendentals.

"Early Transcendentals introduce polynomials, rational functions, exponentials, logarithms, and trigonometric functions at the beginning of the course and use them as examples when developing differential calculus. Whereas, Late Transcendentals develop differential calculus using only polynomials and rational functions as examples and introduce the rest afterwards" [19].

\section{FINDINGS}

\subsection{High-level Calculus Textbook Investigation}

There are forty-three accredited undergraduate engineering universities in Canada, from those forty-three we found textbooks for thirty-nine of those institutions. Two of those institutions chose to create their own course notes for teaching; two institutions did not have information on textbooks that could be found; emails were sent to these institutions for follow-up with no return information. For this study we did not investigate the course notes.

In total, there are fifteen different textbooks used across Canada, the most popular textbook being, Calculus: Early Transcendentals by James Stewart; this book was used at a total of ten different institutions. Of the fifteen textbooks used, two were translated into French; thus, if the authors had distinguished these there would have been in total seventeen texts used across Canada.

There was a wide variety in the number of pages in the textbooks. The longest (largest) was 1368 pages, Calculus, Early Transcendentals by James Stewart; the shortest was 464 pages, the French adaption of James Stewart's Single Variable Calculus, Early Transcendentals, adapted by Stéphane Beauregard and Chantal Trudel. On average the textbooks were 981 pages. The author's find it interesting that both the French versions of their English companions were shorter than the English versions of said textbooks.

There were two main publishers of these calculus textbooks, Pearson (published 6 of the 15 textbooks), and Brooks/Cole Publishing, which is now known as Cengage (published 5 of the 15 textbooks). Most of these textbooks were subsequent editions of previous versions. All of the textbooks contained problem sets, most with 'odd answers' included, and the ability to purchase a separate solution manual. In addition, all the textbooks now have 'online' web components to them as well, often to be purchased as separate, supplemental material.

Most of these textbooks had several chapters divided into sections. Likely these chapters were grouped in succession as a method of teaching, as was mentioned above. Along with the various chapters, many of these textbooks had several appendices to accompany these chapters. These appendices were both in support of the material in the textbook and provided deeper, more advanced learning for readers. There were on average fifteen chapters in each textbook plus appendices.

Textbooks, especially calculus textbooks, have been around for ages. Not surprisingly, many of these textbooks had been through several revisions, as expressed by edition number. Some of the books were into their seventh and eighth revision, where as others were quite new and only in their first or second editions. On average the textbooks were in their fifth revisions. The year of the textbooks last revision is shown in the table attached in the appendix. It is interesting to note that the oldest and newest calculus textbooks (based on their revisions as stated as editions) were classified as 'applied in engineering;' perhaps that means there is an increasing demand for engineering calculus textbooks that are rooted in engineering, not just abstract/pure math.

The textbooks were finally analyzed concerning their mathematics teaching methods. The authors divided these mathematics teaching methods into three categories, abstract, applied and applied with engineering examples. Not surprisingly, most of these first-year calculus textbooks were classified as abstract, that is they are taught with traditional, pure mathematics with a focus on firstprinciples and technical competence; nine of the evaluated textbooks were classified as abstract. Textbooks classified as applied provided a first principles approach, but in their descriptions, these books had examples that were from the various sciences; three of these textbooks were classified as applied. The last category, applied with examples rooted in engineering, were similar to the applied examples, but specifically listed engineering examples in their descriptions; there were three of these textbooks as part of the evaluation.

The results are summarized in a table in the appendix.

\subsection{Detailed Calculus Textbook Investigation}

The following four textbooks were chosen for this investigation from the following categories:

- Abstract: Calculus: Early Transcendentals by James Stewart

- Applied: Calculus: A Complete Course by R.A. Adams and Christopher Essex

- Applied rooted in Engineering: Calculus for Scientists and Engineers by William L. Briggs, Lyle Cochran, Bernard Gillett, and Eric Schulz

Finally, an additional book categorized as 'abstract' was chosen, James Stewart's Calculus for comparison, as it does not treat transcendentals early.

Derivatives were chosen as the means for comparison amongst these textbooks. While other calculus topics were considered, such as integrals, partial differential equations, vectors, etc., the decision was to investigate the chapter on 
derivatives. The fundamental theorem of calculus links the concept of differentiating a function with the concept of integrating a function. Since derivatives are often taught first, which introduces the anti-derivative, which in turn introduces integrals, it was chosen for comparison in the textbooks. Somewhat like the addition to subtraction or multiplication to division.

The treatment of 'derivatives' was analyzed for comparison. Aside from Calculus: Early Transcendentals each book considered the teaching of derivatives as a standalone chapter. In Calculus: Early Transcendentals the derivative is introduced in the Limits and Derivatives chapter. Derivatives are a continuation of the understanding of limits, which Briggs, Cochran, Gillet and Shultz succinctly summarize, "All of calculus is based on the idea of a limit... which underlies the two fundamental operations of calculus: differentiation and integration. Once you understand limits the door to calculus stands open; the first task is to introduce the fundamental of the derivative." We chose the derivative because as evidenced in all of these textbooks, it is taught before the integral.

In addition to the 'demographic' data collected above, such as the number of pages in the chapter, a number of sections in the derivatives chapter, we also looked at the number of chapters dedicated to teaching the derivative in the book. The two books categorized as 'applied' and 'applied rooted in engineering' both had two chapters on derivatives, the introduction plus all the associated rules and a chapter on 'applications of the derivative.' Both the Stewart books had these two chapters; in addition, these two books included a chapter on Differentiation Rules. Calculus: Early Transcendentals, was slightly longer having treated derivatives as part of the chapter on limits and continuity.

These chapters on derivatives were also evaluated on how they approached examples and problem sets. While each of these books was categorized slightly differently, all of them approached both their examples and problem sets with examples that started in the abstract working toward the applied and applied rooted in engineering in the Briggs, Cochran, Gillet and Shultz textbook. Perhaps it is because the derivative is such a fundamental concept that it made sense to start a high level and 'zoom' the lens into the applied as the student became more familiar with the material. We agree with the literature that says there is a place both for rote rehearsal and applied problems sets [4, 20, 21]

Finally, we choose to include quotes both from the beginning of the chapter on derivatives and the beginning of the calculus textbooks. These were chosen for their beauty and simplicity in describing the art that is calculus. Of note, Calculus: Early Transcendentals, did the best job at tying together: where the material came from (derivatives as they relate to limits), what a student would learn (about the derivative), and how it applied later (to differential equations). Patterning material such that it relates succinctly is often beneficial to students [22].

The results of the derivative chapters are summarized in a table in the appendix.

\section{DISCUSSION}

What is the best type of textbook for first-year engineering calculus, one that teaches toward the abstract mathematics, or conversely, at the other end of the spectrum, taught through applied mathematic examples that are rooted in engineering, but perhaps, without enough pure mathematics?

Perhaps the best is a textbook that can move along this spectrum. One teaching method, concreteness fading, starts with an applied example students can relate to and 'zooming out' so the student can see where the theory is rooted in mathematics. The three stages of concreteness fading include: first, an enactive form, which is a physical, concrete model of the concept; secondly, an iconic form, which is a graphic or pictorial model; and finally, a symbolic form, which is an abstract model of the concept [23]. "The idea is to start with a concrete, recognizable form and gradually strip away irrelevant details to end with the most economic, abstract form" [23]. Fyfe and McNeil state that this concreteness fading promotes better mathematical transfer [23].

Engineers do need to be strong mathematicians, every decision an engineer makes is rooted in a mathematical model [24]. Thus, engineers need to not only understand the methods from which they calculate (i.e. the formula they use to problem solve) but also where that method comes from in mathematical theory.

\section{CONCLUSIONS}

Do you even need a textbook? Has the textbook merely become a relic of the past? Admittedly, you could choose to teach the course without a textbook. There are many resources available online, or you could develop your own. Indeed, it has even been predicted that the death of the textbook may be coming soon [25]. However, teaching without a textbook is still a somewhat radical idea, and we acknowledge that textbooks have great potential to be useful.

A number of students have shown that educators at all levels rely on textbooks, especially when they are designing a new course or are new to teaching a course. Decisions regarding course structure and order are of particular importance [26], and these are often made based on textbooks. Despite the fact that the order of the material presented in mathematics textbooks has been argued to be arbitrary [27], Love and Pimm [28] suggest that textbooks contain control structures that order the material, such as their linear design, and that textbook authors are well aware when writing texts that they are for teachers as well 
as students [28]. Mesa and Griffiths [29] have studied textbooks as instruments that mediate three relationships: the instructor to the content of the course (i.e., textbooks help to structure the course), the instructor to the student (i.e., the textbook can help the instructor help students learn), and the instructor to himself or herself (i.e., the textbook can help the instructor reflect on the course) [29].

While textbooks are not a necessarily component of a course, they can provide a useful framework for teaching and help in making important instructional decisions. Thus, we offer below first some warnings regarding textbooks and then some helpful suggestions for you in making your choice.

As reflected above, textbooks have great potential to be useful, and many past texts have done fairly well, but we believe that it is possible to do better. Below are three considerations for you as you select a textbook framed for engineering mathematics, namely calculus, but also more broadly.

1. Who is the intended audience? Textbooks can, and do, serve a purpose for small, specialized to large, general classes. The type of textbook one picks needs to meet the needs of the course and the average student. Large textbooks, similar to the engineering mathematics calculus books above can serve several types of students, especially when used in conjunction online material, both from and outside of the textbooks. A notes package, a collection of chapters from textbooks may be better suited to a smaller, more specialized class.

2. What is the frame of reference for the textbook? From the lens of calculus for engineering mathematics, does it frame mathematics in the context of predicting outcomes and making decisions, or is it instead written as though the students could be future mathematicians, or economists, or physicists? Gardner [30] suggests that universities should teach broad, complex relationships and that textbooks should reflect the beliefs about these relationships [30]; one such central belief is that decision-making based on mathematical modelling is essential in engineering. The textbook should also be tied in with the course objectives; can the textbook answer the questions you are working through in your course.

3. Does the textbook make connections? That is, does the textbook connect the mathematics to the real world, to humanity, to students' other engineering courses? Engineers do not use mathematics for the sake of mathematics, but rather in a way that is emphatically grounded in the world around them. Without these connections, students learn only mechanical proficiency but lose the power of mathematical modelling.

4. Does the textbook ask open-ended questions? Such tasks encourage students to develop their own approaches; as Herbel-Eisenmann [13] discusses, good textbooks encourage students to use their own reasoning in making decisions, rather than simply being authoritative [13]. Similarly, Raman [31] emphasizes how textbooks should connect the informal aspects of mathematics - intuitions, hunches - with the formality of proofs and rigour[31]. This is true not just of calculus textbooks, and other mathematical textbooks, but any subject. Ideally, the goal is to get students to think deeply and broadly about what they are studying.

5. Where are you, or your fellow instructions, in their teaching careers with this course? How long have you been practicing not just your teaching, but the material you are teaching. A course like introductory calculus in an undergraduate engineering curriculum is a somewhat static course; you can get better at teaching the same material year after year.

Note that we make no suggestions regarding the mathematical content of these texts; a calculus textbook, for example, should, of course, contain typical sections on differential and integration, and contain all of the rigour, analysis, and mathematical proficiency of many calculus texts! What might differ between a textbook for which you answer 'yes' to the above questions and one for which you answer 'no' is the context in which these are presented. Framing the content in a way that is meaningful to engineering students - that is, in a way that helps them learn how to make informed, responsible, ethical decisions based on the anticipated societal consequences - can motivate your students and ground the mathematical material in the bigger picture of their studies.

Even more broadly, these considerations can apply to textbook choices for courses beyond engineering mathematics. No matter the course, textbooks should frame the content in a way that is relevant in the field; they should make connections between the theory and its applications, and they should push students to engage in critical thinking rather than in passive learning. Textbooks, while not a necessity, are an opportunity to help students learn and prepare for future challenges.

\section{References}

[1] Engineers Canada: About Accreditation. 2017.

[2] International Engineering Alliance: 25 Years. The Washington Accord: 1989-2014 Celebrating International Engineering Education Standards and Recognition. International Engineering Alliance Secretariat, 2015.

[3] Suzanne Hidi and Judith M. Harackiewicz: "Motivating the Academically Unmotivated: A Critical Issue for the 21st Century". Rev. Educ. Res., vol. 70, no. 2, 2000, pp. 151-179. 
[4] Jo Boaler: Mathematical Mindsets. San Francisco: Joseey-Bass, 2016.

[5] Bryan Karney and Anne Mather: "Math, policy and responsible action". Eng. Dimens., 2011, pp. 46-49.

[6] Steven Krumholz et al.: Designing an Engineering Entrepreneurship Curriculum for Olin College. Montreal, 2002.

[7] D.J.: "Mathematical Methods for Physicists". Am. J. Phys., vol. 4, no. 67, 1999, pp. 165.

[8] Christine S. Lee et al.: "Indispensable Resource? A Phenomenological Study of Textbook Use in Engineering Problem Solving". J. Eng. Educ., vol. 102, no. 2, 2013, pp. 269-288.

[9] G. Kulm: "Evaluating Mathematical Textbooks". Basic Educ., vol. 43, no. 9, 1999, pp. 61.

[10] Tom Hutchinson and Eunice Torres: "The textbook as agent of change". \{ELT\} J., vol. 48, no. 4, 1994, pp. 315328.

[11] Laurie Haight Keenan: "Textbook Pedagogy: Some Considerations". Class. World, vol. 106, no. 1, 2012, pp. 117-121.

[12] Elizabeth Dobler: "E-Textbooks: A Personalized Learning Experience or a Digital Distraction?". $J$. Adolesc. Adult Lit. (International Lit. Assoc., vol. 58, no. 6, 2015, pp. 482-491.

[13] Beth A. Herbel-Eisenmann: "From Intended Curriculum to Written Curriculum: Examining the 'Voice' of a Mathematics Textbook". J. Res. Math. Educ., vol. 38, no. 4, 2007, pp. 344-369.

[14] Thomas Bartlett: Selling Out: a Textbook Example - The Chronicle of Higher Education. 2003.

[15] Thomas Berry et al.: "An Exploratory Analysis of Textbook Usage and Study Habits: Misperceptions and Barriers to Success". Coll. Teach., vol. 59, no. 1, 2010, pp. 31-39.

[16] Aaron Weinberg and Emilie Wiesner: "Understanding mathematics textbooks through reader-oriented theory". Educ. Stud. Math., vol. 76, no. 1, 2010, pp. 49-63.

[17] Mary D. Shepherd et al.: "University Students\{ltextquotesingle\} Reading of Their First-Year Mathematics Textbooks". Math. Think. Learn., vol. 14, no. 3, 2012, pp. 226-256.

[18] Leslie Mustoe: "The Mathematics Background of Undergraduate Engineers". Int. J. Electr. Eng. Educ., vol. 39, no. 3, 2002, pp. 192-200.

[19] Stack Exchange: Math Educators. 2017.

[20] Marni Vegessi Jamieson and John M. Shaw: Applying Metacognitive Strategies to Teaching Engineering, Innovation, Deign, and Leadership. Toronto, 2017.

[21] K. Anders Ericsson: Attaining Excellence Through Deliberate Practice: Insights from the Study of Expert Performance. Blackwell Publishers Ltd, no date, pp. 4 37.

[22] Lolita Paff: Aligning Student and Faculty Perceptions of Rigor. Madison: Magna Online Seminars, 2017.

[23] Emily R. Fyfe et al.: "Concreteness Fading in Mathematics and Science Instruction: a Systematic Review". Educ. Psychol. Rev., vol. 26, no. 1, 2014, pp. 9-25.

[24] Bryan Karney et al.: A Decision-Making Framework for Engineering Mathematics Education: A Critical Literature Review. Toronto: CEEA, 2017.
[25] Judy Salpeter: "Textbook Deathwatch". Tech Learn., vol. 30, no. 1, 2009, pp. 26-29.

[26] John Bransford et al.: How People Learn. National Academies Press, 1999.

[27] Jan Mokros: "Where's the Math?". Educ. Dig., vol. 60, no. 3, 1994, pp. 61 .

[28] Eric Love and David Pimm: 'This is so': A text on texts. Seville: Springer, 1996.

[29] Vilma Mesa and Brett Griffiths: "Textbook mediation of teaching: an example from tertiary mathematics instructors". Educ. Stud. Math., vol. 79, no. 1, 2011, pp. 85-107.

[30] Paul L. Gardner: "The representation of sciencetechnology relationships in Canadian physics textbooks". Int. J. Sci. Educ., vol. 21, no. 3, 1999, pp. 329-347.

[31] Manya Raman: "Coordinating informal and formal aspects of mathematics: student behavior and textbook messages". J. Math. Behav., vol. 21, no. 2, 2002, pp. 135-150.

\section{APPENDIX A: CANADIAN ENGINEERING CALCULUS TEXTBOOK DESCRIPTIONS}

\section{The ABC's of Calculus by Angelo B. Mingarelli}

"The $\mathrm{ABCs}$ of Calculus guides students in their quest towards understanding Calculus, and ultimately towards solving a variety of Calculus problems. Understanding that diversity of students in the Calculus classroom, the material in the text is presented through verbal, theoretical, practical, numerical and geometrical approaches, in order to satisfy varying learning styles. The text provides a much valued review of basic material while working towards a goal that includes the fostering of a feeling for what Calculus is, what it does, and how you can correctly solve the problems it generates. With many completely solved examples, and hundreds of opportunities to apply concepts through problems, students will quickly build their confidence, and ultimately succeed in Calculus"

Description: Applied

Calculus: Early Transcendentals by James Stewart

"Success in your calculus course starts here! James Stewart's CALCULUS: EARLY TRANSCENDENTALS texts are world-wide best-sellers for a reason: they are clear, accurate, and filled with relevant, real-world examples. With CALCULUS: EARLY TRANSCENDENTALS, Eighth Edition, Stewart conveys not only the utility of calculus to help you develop technical competence, but also gives you an appreciation for the intrinsic beauty of the subject. His patient examples and built-in learning aids will help you build your mathematical confidence and achieve your goals in the course." 
Description: Abstract

Calculus: Single Variable by R.A. Adams and

C. Essex

For the three-semester calculus course.

Proven in North America and abroad, this classic text has earned a reputation for excellent accuracy and mathematical rigour. Previous editions have been praised for providing complete and precise statements of theorems, using geometric reasoning in applied problems, and for offering a range of applications across the sciences. Written in a clear, coherent, and readable form, Calculus: Single Variable makes student comprehension a clear priority.

Description: Applied

Calculus: Concepts and Contexts by James

Stewart

Stewart's CALCULUS: CONCEPTS AND CONTEXTS, FOURTH EDITION offers a streamlined approach to teaching calculus, focusing on major concepts and supporting those with precise definitions, patient explanations, and carefully graded problems. CALCULUS: CONCEPTS AND CONTEXTS is highly regarded because this text offers a balance of theory and conceptual work to satisfy more progressive programs as well as those who are more comfortable teaching in a more traditional fashion. Each title is just one component in a comprehensive calculus course program that carefully integrates and coordinates print, media, and technology products for successful teaching and learning.

Description: Applied

Calculus for Scientists and Engineers by Briggs, Cochrane \& Gillet's

For a three-semester or four-quarter calculus course covering single variable and multivariable calculus for mathematics, engineering, and science majors.

Briggs/Cochran is the most successful new calculus series published in the last two decades. The authors' years of teaching experience resulted in a text that reflects how students generally use a textbook: they start in the exercises and refer back to the narrative for help as needed. The text therefore builds from a foundation of meticulously crafted exercise sets, then draws students into the narrative through writing that reflects the voice of the instructor, examples that are stepped out and thoughtfully annotated, and figures that are designed to teach rather than simply supplement the narrative. The authors appeal to students' geometric intuition to introduce fundamental concepts, laying a foundation for the rigorous development that follows.

Description: Applied in Engineering

\section{Calculus for Engineers by Donald Trim}

Calculus for Engineers, Fourth Canadian Edition, is appropriate for first-year university-level engineering/physical science students who are studying calculus.

Using an early transcendental approach, Trim emphasizes practical applications, many of which are drawn from various engineering fields. Students begin with basic practice drills and then progress to problems that require the integration of information learned in previous chapters. In this way, students develop an understanding of the mathematical procedure, rather than simply plugging numbers into formulae.

Description: Applied in Engineering

\section{Calculus, Early Transcendentals, by Edwards \& Penney}

This text is rigorous, fairly traditional and is appropriate for engineering and science calculus tracks. Hallmarks are accuracy, strong engineering and science applications, deep problem sets (in quantity, depth, and range), and spectacular visuals

Description: Applied

\section{Single Variable Calculus, Early} Transcendentals, by James Stewart

Success in your calculus course starts here! James Stewart's CALCULUS: EARLY TRANSCENDENTALS texts are world-wide best-sellers for a reason: they are clear, accurate, and filled with relevant, real-world examples. With SINGLE VARIABLE CALCULUS: EARLY TRANSCENDENTALS, Seventh Edition, Stewart conveys not only the utility of calculus to help you develop technical competence, but also gives you an appreciation for the intrinsic beauty of the subject. His patient examples and built-in learning aids will help you build your mathematical confidence and achieve your goals in the course!

Description: Abstract

Calculus, A Complete Course by R.A. Adams and C. Essex

Proven in North America and abroad, this classic text has earned a reputation for excellent accuracy and mathematical rigour. Previous editions have been praised for providing complete and precise statements of theorems, using geometric reasoning in applied problems, and for offering a range of applications across the sciences. Written in a clear, coherent, and readable form, Calculus: A Complete Course makes student comprehension a clear priority. 
Description: Applied

Advanced Engineering Mathematics, E. Kreyszig, J. Wiley \& Sons

known for its comprehensive coverage, careful and correct mathematics, outstanding exercises, and self-contained subject matter parts for maximum flexibility. The new edition continues with the tradition of providing instructors and students with a comprehensive and up-to-date resource for teaching and learning engineering mathematics, that is, applied mathematics for engineers and physicists, mathematicians and computer scientists, as well as members of other disciplines. Description: Applied in Engineering

\section{Multivariable Calculus, J. Stewart}

Success in your calculus course starts here! James Stewart's CALCULUS texts are world-wide best-sellers for a reason: they are clear, accurate, and filled with relevant, real-world examples. With MULTIVARIABLE CALCULUS, Seventh Edition, Stewart conveys not only the utility of calculus to help you develop technical competence, but also gives you an appreciation for the intrinsic beauty of the subject. His patient examples and built-in learning aids will help you build your mathematical confidence and achieve your goals in the course!

Description: Applied

Analyse, concepts et contextes, Volume 2 : Fonctions de plusieurs variables, J. Stewart. De Boeck

La nouveauté de cette $3 e$ édition est la possibilité de s'entraîner avec TEC : "Techniques pour enrichir ses compétences". TEC est un espèce de laboratoire dans lequel les étudiants peuvent explorer des séquences choisies et également des exercices. TEC est disponible sur www.stewartcalculus.com dans le livre un logo TEC vous renvoie vers le site.

La compréhension des concepts, tel est l'objectif de ce manuel. En conséquence, chaque concept est patiemment introduit et formulé verbalement, visuellement, numériquement et algébriquement avant que n'apparaisse sa définition formelle. Des exemples bien choisis préparent souvent l'énoncé des théorèmes pour justifier la pertinence de leurs hypothèses. L'apprentissage au raisonnement est soutenu par les démonstrations (parfois reportées en annexe pour ne pas perdre le fil du discours).

L'apprenant, devenu maître des concepts autant que des techniques, sera capable de choisir et d'utiliser les outils du calcul différentiel et intégral dans des contextes divers. L'apprentissage actif, de type exploratoire et heuristique, est favorisé par l'utilisation fréquente et à bon escient des calculatrices graphiques et/ou logiciels de calcul symbolique. Lors de chaque résolution de problèmes, l'accent est mis sur la méthode suivie ou l'activité de recherche mobilisée.

Nouvelle édition revue et enrichie de $10 \%$ d'exercices supplémentaires, les deux volumes de cet ouvrage s'adressent aux étudiants de premier cycle universitaire qui, quelle que soit leur orientation, y trouveront des applications, tant sont divers et nombreux les domaines abordés dans les exercices. Le premier volume s'adresse également aux étudiants des années terminales de l'enseignement secondaire.

Description: Applied (same as Calculus: Concepts and Contexts by James Stewart)

Fonctions de plusieurs variables, Auteurs par Hugues-Hallet, Gleason and McCallum

Ce manuel du Projet Harvard présente le calcul à plusieurs variables, dans une démarche alliant nouvelles technologies et résolution de problèmes. La $2^{\mathrm{e}}$ édition de Fonctions de plusieurs variables contient :

- Un texte entièrement réécrit, beaucoup plus clair et direct, qui facilite grandement la lecture et la compréhension ;

- De nouveaux contenus : séries, approximations, équations différentielles de premier ordre ;

- Une nouvelle rubrique Vérifiez vos connaissances qui termine chaque chapitre et permet à l'étudiant de mesurer sa compréhension des concepts ;

- $15 \%$ de nouveaux exercices, dont chaque série est maintenant divisée en deux catégories : exercices de routine et problèmes.

Description: Abstract

Calculus (Early Transcendentals) with WebAssign Access Card by Jon Rogawski

The most successful calculus book of its generation, Jon Rogawski's Calculus offers an ideal balance of formal precision and dedicated conceptual focus, helping students build strong computational skills while continually reinforcing the relevance of calculus to their future studies and their lives.

Guided by new author Colin Adams, the new edition stays true to the late Jon Rogawski's refreshing and highly effective approach, while drawing on extensive instructor and student feedback, and Adams' three decades as a calculus teacher and author of math books for general 
audiences.

W. H. Freeman/Macmillan and WebAssign have partnered to deliver WebAssign Premium - a comprehensive and flexible suite of resources for your calculus course. Combining the most widely used online homework platform with the authoritative and interactive content from the textbook, WebAssign Premium extends and enhances the classroom experience for instructors and students.

Description: Applied

Calculus: Early Transcendentals - single variable by W.Briggs and L. Cochrane

Drawing on their decades of teaching experience, William Briggs and Lyle Cochran have created a calculus text that carries the teacher's voice beyond the classroom. That voice-evident in the narrative, the figures, and the questions interspersed in the narrative-is a master teacher leading readers to deeper levels of understanding. The authors appeal to readers' geometric intuition to introduce fundamental concepts and lay the foundation for the more rigorous development that follows. Comprehensive exercise sets have received praise for their creativity, quality, and scope

Description: Abstract

\section{Calculus by James Stewart}

Stewart conveys not only the utility of calculus to help you develop technical competence, but also gives you an appreciation for the intrinsic beauty of the subject. His patient examples and built-in learning aids will help you build your mathematical confidence and achieve your goals in the course!

Description: Abstract

Integral Calculus, James Stewart

Cette première édition québécoise de Calculus s'adresse aux étudiants du collégial. Revue et adaptée, elle part de l'idée qu'on peut atteindre la compréhension conceptuelle tout en poursuivant les meilleures traditions du calcul intégral.

En plus de conserver l'approche et la rigueur scientifique de l'ouvrage de James Stewart, elle présente une réorganisation, notamment en ce qui concerne les notions sur les suites et les séries, ainsi que des exercices et des problèmes supplémentaires.

Description: Abstract (same as Calculus by James Stewart) 
APPENDIX B: FIRST YEAR CALCULUS TEXTBOOK GENERAL INFO

\begin{tabular}{|c|c|c|c|c|c|c|c|c|}
\hline & First Year Calculus Textbooks [Title \& Author] & $\frac{\frac{\text { \# of }}{\text { School's }}}{\text { Used }}$ & $\frac{\# \quad \text { of }}{\text { Pages }}$ & $\begin{array}{c}\text { \# of } \\
\text { Chapters }\end{array}$ & $\underline{\text { Current }}$ & Publisher & Category & Schools using this Textbook \\
\hline 1 & Advanced Engineering Mathematics by Erwin Kreyszig & 1 & 1280 & 25 & 10th (2011) & Wiley & Applied (Eng) & [ULaval] \\
\hline 2 & $\begin{array}{l}\text { Analyse: concepts et contextes - Volume 2: Fonctions de } \\
\text { Plusieurs Variables by James Stewart }\end{array}$ & 6 & 976 & 18 & 3rd (2011) & De Boeck & Abstract & {$[\cup Q]$} \\
\hline 3 & Calculus by James Stewart & 1 & 1368 & 17 & 8th (2015) & Brooks Cole & Abstract & [Uregina] \\
\hline 4 & Calculus for Engineers by Donald Trim & 2 & 1216 & 15 & 4th (2007) & $\begin{array}{l}\text { Pearson } \\
\text { Canada }\end{array}$ & Applied (Eng) & [UW] [UManitoba] \\
\hline 5 & $\begin{array}{l}\text { Calculus for Scientists and Engineers by William L. Briggs, Lyle } \\
\text { Cochran, Bernard Gillett, and Eric Schulz }\end{array}$ & 1 & 1200 & 16 & 1st (2013) & Pearson & Applied (Eng) & [UofT] \\
\hline 6 & $\begin{array}{l}\text { Calculus: A Complete Course by R.A. Adams and Christopher } \\
\text { Essex }\end{array}$ & 3 & 1152 & 18 & 8th (2014) & Pearson & Applied & [Ucalgary] [USask][UWO] \\
\hline 7 & Calculus: Concepts and Contexts by James Stewart & 1 & 1152 & 13 & 4th (2009) & Brooks Cole & Abstract & [UOttawa] \\
\hline 8 & $\begin{array}{l}\text { Calculus: Early Transcendentals by C. Henry Edwards and } \\
\text { David E. Penny }\end{array}$ & 2 & 1344 & 14 & 7th (2007) & Pearson & Applied & [BCIT] [Uvic] \\
\hline 9 & Calculus: Early Transcendentals by James Stewart & 10 & 1368 & 17 & 8th (2015) & Brooks Cole & Abstract & $\begin{array}{c}\text { [Lakehead] [Mcmaster] } \\
\text { [Queen's][Ryerson][UOIT][YorkU] } \\
\text { [SFU][UA] [UNB][Guelph] }\end{array}$ \\
\hline 10 & Calculus: Early Transcendentals by Jon Rogawski & 1 & 1050 & 17 & 3rd (2015) & $\begin{array}{l}\text { W. H. } \\
\text { Freeman }\end{array}$ & Abstract & [MEM] \\
\hline 11 & Calculus: Single Variable by R.A. Adams and C. Essex & 1 & 683 & 18 & 8th (2013) & $\begin{array}{l}\text { Pearson } \\
\text { Canada }\end{array}$ & Abstract & [Laurentian] \\
\hline 12 & $\begin{array}{l}\text { Calculus:Early transcendentals by William L. Briggs, Lyle } \\
\text { Cochran and Bernard Gillett }\end{array}$ & 1 & 816 & 10 & 1st (2010) & Pearson & Abstract & [Dalhousie] \\
\hline 13 & $\begin{array}{l}\text { Fonctions de Plusieurs Variables by Deborah Hughes-Hallett, } \\
\text { Andrew M. Gleason, and William G. McCallum }\end{array}$ & 1 & 650 & 12 & 2nd (2005) & $\begin{array}{l}\text { Cheneliére } \\
\text { Education }\end{array}$ & Abstract & [Sherbooke] \\
\hline 14 & Calcul Intégral by James Stewart & 1 & 464 & 6 & 1st (2014) & Modulo & Abstract & {$[\mathrm{MON}]$} \\
\hline 15 & Multivariable Calculus by James Stewart & 1 & 600 & 18 & 7th (2011) & Brooks Cole & Abstract & [Polymtl] \\
\hline 16 & $\begin{array}{l}\text { Single Variable Calculus: Early Transcendentals by James } \\
\text { Stewart }\end{array}$ & 4 & 624 & 17 & 8th (2016) & Brooks Cole & Abstract & $\begin{array}{c}\text { [UNBC] [Concordia] [Mcgill] } \\
\text { [UWindsor] }\end{array}$ \\
\hline 17 & The ABC's of Calculus by A. Minarelli & 1 & 748 & 11 & 1st (2016) & $\begin{array}{l}\text { The Nolan } \\
\text { Company }\end{array}$ & Applied & [Carleton] \\
\hline
\end{tabular}


APPENDIX C: FIRST YEAR CALCULUS TEXTBOOKS SPECIFIC INFORMATION

\begin{tabular}{|c|c|c|c|c|c|c|c|c|c|}
\hline & $\begin{array}{l}\frac{\text { First Year }}{\text { Calculus }} \\
\text { Textbooks] }\end{array}$ & Category & $\frac{\text { \# of Pages }}{\frac{\text { in this }}{\text { Chapter }}}$ & $\begin{array}{l}\frac{\# \text { of }}{\text { Sections in }} \\
\frac{\text { this }}{\text { Chapter }}\end{array}$ & $\begin{array}{l}\frac{\# \text { of }}{\text { Chapters }} \\
\text { Dedicated to } \\
\text { Derivatives }\end{array}$ & $\frac{\text { Problem }}{\text { sets start }}$ & $\frac{\frac{\text { Examples }}{\text { are rooted }}}{\text { in ... }}$ & $\begin{array}{c}\text { Upfront Introduction/Definition of The } \\
\text { Derivative }\end{array}$ & Quote from the book \\
\hline 1 & $\begin{array}{l}\text { Calculus by } \\
\text { James Stewart }\end{array}$ & Abstract & 98 pages & 9 sections & 3 chapters & Abstract & Abstract & $\begin{array}{l}\text { "The central concept of differential } \\
\text { calculus is the derivative, which is an } \\
\text { outgrowth of the velocities and slopes of } \\
\text { tangents that we considered in the } \\
\text { previous chapter. After learning how to } \\
\text { calculate derivatives, we use them to solve } \\
\text { problems involving rates of change and } \\
\text { approximations of functions." }\end{array}$ & $\begin{array}{l}\text { "The emphasis is on understanding } \\
\text { concepts. ..Calculus teaches you to think } \\
\text { logically" }\end{array}$ \\
\hline 2 & $\begin{array}{l}\text { Calculus: Early } \\
\text { Transcendent } \\
\text { al by James } \\
\text { Stewart }\end{array}$ & Abstract & $\begin{array}{l}104^{*} \\
\text { Pages }\end{array}$ & $\begin{array}{c}13 \\
\text { sections }\end{array}$ & $\begin{array}{c}3.5^{*} \\
\text { chapters }\end{array}$ & Abstract & Abstract & $\begin{array}{l}\text { "The central concept of differential } \\
\text { calculus is the derivative, which is an } \\
\text { outgrowth of the velocities and slopes of } \\
\text { tangents that we considered in the } \\
\text { previous chapter. After learning how to } \\
\text { calculate derivatives, we use them to solve } \\
\text { problems involving rates of change and } \\
\text { approximations of functions." }\end{array}$ & $\begin{array}{l}\text { "Calculus is fundamentally different from } \\
\text { the mathematics that you have studied } \\
\text { previously: calculus is less static and more } \\
\text { dynamic." } \\
\text { *Differentiation is introduced in the last two } \\
\text { sections of the Limits chapter. }\end{array}$ \\
\hline 3 & $\begin{array}{l}\text { Calculus: A } \\
\text { Complete } \\
\text { Course by R.A. } \\
\text { Adams and } \\
\text { Christopher } \\
\text { Essex }\end{array}$ & Applied & 68 pages & $\begin{array}{c}11 \\
\text { sections }\end{array}$ & 2 chapters & Abstract & Abstract & $\begin{array}{l}\text { "Two fundamental problems are } \\
\text { considered in calculus...The problem of } \\
\text { slopes... solved through differential } \\
\text { calculus, which has many applications in } \\
\text { mathematics and other disciplines ... the } \\
\text { problem of areas... solved through integral } \\
\text { calculus }\end{array}$ & $\begin{array}{l}\text { "Calculus is in many respects a classical } \\
\text { subject....It is very much a centerpiece of the } \\
\text { human legacy, with a cultural significance } \\
\text { that transcends borders. It is taught in every } \\
\text { institution of higher learning in the world, } \\
\text { because it is essential to basic human } \\
\text { thought in engineering, science, and many } \\
\text { social sciences." }\end{array}$ \\
\hline 4 & $\begin{array}{l}\text { Calculus for } \\
\text { Scientists and } \\
\text { Engineers by } \\
\text { William L. } \\
\text { Briggs, Lyle } \\
\text { Cochran, } \\
\text { Bernard } \\
\text { Gillett, and } \\
\text { Eric Schulz }\end{array}$ & $\begin{array}{l}\text { Applied } \\
\text { (Eng) }\end{array}$ & 133 pages & $\begin{array}{c}10 \\
\text { sections }\end{array}$ & 2 chapters & Abstract & Abstract & $\begin{array}{l}\text { "All of calculus is based on the idea of a } \\
\text { limit... which underlie the two } \\
\text { fundamental operations of calculus: } \\
\text { differentiation and integration. Once you } \\
\text { understand limits the door to calculus } \\
\text { stands open; the first task is to introduce } \\
\text { the fundamental of the derivative." }\end{array}$ & $\begin{array}{l}\text { "All topics are introduced through concrete } \\
\text { examples, applications, and analogies rather } \\
\text { than through abstract arguments." }\end{array}$ \\
\hline
\end{tabular}

